\title{
Ética e coprodução de serviços públicos: uma fundamentação a partir de Habermas
}

\author{
Ethics and coproduction of public services: a rationale from Habermas \\ Clenia De Mattia ${ }^{1}$ \\ Marcello B. Zappellini ${ }^{2}$
}

\section{Resumo}

A produção de bens e serviços públicos é um processo que pode ser organizado de diferentes formas na sociedade, sendo necessário determinar formas que satisfaçam não apenas interesses individuais, mas também coletivos. A coprodução é uma estratégia em que a definição dos bens e serviços a serem produzidos pela administração pública exige um processo democrático e participativo que envolva os cidadãos. Uma revisão histórica do conceito de coprodução é feita, visando definir suas características e seu funcionamento, destacando-se o caráter procedimental do mesmo. Nesse sentido, a organização dos esforços dos cidadãos deve obedecer a regras morais, e este artigo tem por objetivo buscar um fundamento ético para a coprodução. Como tal, a ética discursiva de Habermas é debatida como uma forma de nortear os procedimentos de coprodução. O caráter democrático da ética discursiva e da coprodução é discutido no sentido de demonstrar a congruência entre as duas teorias. $O$ artigo, elaborado na forma de um ensaio teórico, conclui que, embora existam aspectos na teoria de Habermas que não sejam inteiramente adequados ao conceito de coprodução, as possibilidades de sua aplicação são elevadas, justificando discussão mais ampla sobre o tema.

Palavras-chave: Administração pública. Ética da discussão. Coprodução.

\begin{abstract}
The production of public goods and services is a process that can be organized in different ways in society, and it is necessary to determine ways that satisfy not only individual but also collective interests. The co-production is a strategy in which the definition of goods and services to be produced by the Public Administration requires a democratic and participatory process involving citizens. A historical review of the concept of co-production is made in order to define their characteristics and its operation, highlighting its procedural character. In this sense, the organization of citizens' efforts must obey moral rules, and this article has as its objective to search for an ethical foundation to coproduction. As this foundation, Habermas's discursive ethics is discussed as a way to guide co-production procedures. The democratic character of discursive ethics and co-production is discussed to demonstrate the congruence between the two theories. The article, written in the form of a theoretical essay, concludes that, although there are aspects of Habermas' theory that are not entirely adequate to the concept of co-production, the possibilities for its application are high, justifying further discussions on the subject.
\end{abstract}

Keywords: Public Administration. Discursive ethics. Co-production.

Artigo submetido em 30 de dezembro de 2013 e aceito para publicação em 23 de julho de 2014.

\section{DOI: http://dx.doi.org/10.1590/1679-395114417}

1 Doutoranda em Administração pela UFSC; Mestre em Administração pela UFSC. Endereço: CPGA/CSE-UFSC, Campus Universitário, Trindade, CEP 88040-900, Florianópolis - SC, Brasil. E-mail: cleniademattia@gmail.com

2 Doutor em Administração pela UFBA; Professor Assistente da Esag/Udesc. Endereço: Av. Madre Benvenuta, 2037,Itacorubi, CEP 88035-001, Florianópolis - SC, Brasil. E-mail: mbzapelini@hotmail.com 


\section{Introdução}

A tarefa deste artigo é buscar uma fundamentação ética para o conceito de coprodução de serviços públicos. Compreende-se a coprodução como uma forma de produção do bem público que envolve a participação ativa do cidadão, o qual deve tomar parte nos processos de definição e geração desse bem conforme suas necessidades e anseios, que podem assumir diferentes formas e configurações. Ainda embrionário, o conceito se mostra promissor quando se tem em mente a ideia de uma administração pública voltada efetivamente para a satisfação dos desejos e da vontade dos cidadãos.

Como qualquer conceito de administração, a coprodução envolve questões éticas que dizem respeito, por exemplo, a como se deve processar essa participação e como se pode definir o bem público. Uma formulação ou teoria ética que faça frente a tais desafios precisa partir de princípios, haja vista ser a coprodução tanto processo quanto resultado, devendo, portanto, ter um conteúdo deontológico. Nesse sentido, é proposto como fundamento o conceito de ética do discurso ou da discussão de Habermas, que se preocupa com os processos de definição de imperativos éticos capazes de nortear e organizar uma coletividade, e que se mostra eficiente instrumento para lançar a discussão sobre uma visão ética da coprodução, uma vez que a bibliografia sobre o tema se mostra distante ou evasiva.

Assim, este artigo examina, inicialmente, o conceito de coprodução para, em seguida, trabalhar com a definição e os elementos centrais da ética em Habermas, buscando, com isso, a congruência entre essas concepções distintas. Em complemento, ver-se-á sua formulação sobre a democracia, que guarda relação com o tema deste estudo.

Em suas considerações finais, este artigo (que deve ser considerado um ensaio teórico cujos insights são produzidos a partir de revisão de literatura) sintetiza as possibilidades e desafios a serem enfrentados por uma reflexão ética sobre a coprodução.

\section{O Conceito de Coprodução}

A ideia de coprodução surge da constatação de estudiosos de que a produção unilateral de serviços de segurança pública, realizada pelo Estado, não era tão eficiente quanto àquela feita em conjunto com quem recebia os serviços (BRANDSEN e PESTOFF, 2006). O termo é atribuído a Elinor Ostrom para descrever o relacionamento potencial que pode haver entre os agentes públicos ${ }^{3}$ e os usuários do serviço. Para essa autora, a coprodução é um processo que envolve indivíduos que não são servidores públicos na produção de bens e serviços oferecidos pelo governo. Assim, a coprodução é então pensada como uma forma de aumentar a eficiência e a eficácia dos serviços públicos (e não apenas de melhorar sua qualidade) tanto quanto de diminuir gastos do governo, já que cidadãos voluntários atuariam junto com agentes públicos na prestação de serviços.

Alguns autores proeminentes dessa concepção de coprodução, na perspectiva da economia, segundo Salm e Menegasso (2010), são Alford (2002), Brudney e England (1983), Schneider (1987) e Whitaker (1980). Como esclarecem Schommer, Andion, Pinheiro et al. (2011, p. 42), a coprodução vista dessa forma busca "lidar com restrições fiscais e com dificuldades do Estado para responder à diversidade de demandas dos cidadãos/consumidores". Desse modo, pode-se afirmar que é uma perspectiva mais alinhada à teoria da nova gestão pública (new public management), cujo principal objetivo é absorver valores e técnicas de empresas

3

$\mathrm{Na}$ literatura internacional, sobretudo de língua inglesa, é usada frequentemente a expressão "produtores regulares" ou "profissionais". Para facilitar e adequar ao contexto brasileiro, ao longo deste artigo, será utilizada a expressão agente público para identificar aquelas pessoas que trabalham na administração pública, sejam servidores públicos, empregados públicos, concursados ou em cargo comissionado e agentes políticos. 
privadas na administração pública visando reduzir custos e melhorar a qualidade dos serviços para os “consumidores" (DENHARDT, 2012).

Passado o auge de tal olhar gerencial para a gestão pública, estudiosos têm buscado atualmente uma perspectiva mais política, que priorize a democracia e participação. ${ }^{4}$ Aliados a esse novo olhar, percebe-se que muitos autores atribuem uma nova característica para a coprodução, compreendendo-a como um processo que busca o envolvimento do cidadão, não apenas para eficácia e redução de custos para o Estado, mas como direito e dever subjetivo de participar da vida pública em busca de um bem comum. No Brasil, essa é a visão de coprodução compreendida pela maioria dos estudiosos do assunto, a qual se alinha à concepção do Novo Serviço Público.

Enquanto os primeiros trabalhos sobre coprodução buscavam entender sua contribuição para a eficiência, eficácia e redução de custos na prestação de serviços públicos, estudos posteriores fizeram novas indagações acerca do tema. Alford (2002), por exemplo, procura investigar o que induz as pessoas a contribuir com seu tempo e esforço para coprodução. Primeiro de tudo, ele deixa claro que está falando dos clientes do serviço e não de voluntários ou cidadãos, pois há diferenças entre essas três categorias:

a) a coprodução de clientes envolve aquelas pessoas que consomem diretamente o serviço (produtoras e consumidoras);

b) coprodutores voluntários são pessoas que contribuem na prestação de serviços públicos, mesmo não sendo necessariamente consumidores;

c) cidadãos se diferem de clientes, pois seu relacionamento com o governo se baseia no entendimento de que envolve direitos e obrigações. Enquanto os clientes recebem valores privados (e individuais), o cidadão recebe valores públicos (e coletivos).

No Brasil, os estudiosos da coprodução não costumam separar essas categorias, sobretudo, porque se observa que aqui o entendimento de coprodução está mais alinhado com a proposta do Novo Serviço Público. Desse modo, o usuário do serviço público é sempre considerado cidadão, o que traz uma ligação mais forte entre ele e o governo, já que não se trata de mero consumidor. Denhardt (2012, p. 265) esclarece que, nessa perspectiva:

Os servidores públicos não respondem meramente a demanda de consumidores, mas se concentram na construção de relações de confiança e na colaboração com e entre os cidadãos. [...] A cidadania é concebida não como um status legal, mas como uma questão de responsabilidade e moralidade.

Em seu estudo, Alford (2002) procura identificar alguns fatores motivacionais para a coprodução. Ele conclui que quando indivíduos coproduzem, não o fazem necessariamente visando maximizar seu interesse próprio. Por isso, fatores como sanções e recompensas materiais são ineficientes para incentivar a coprodução. Na verdade, a maior motivação está em recompensas não materiais, como socialização e valores expressivos. Entretanto, observa-se que, além da disposição para coproduzir, importa a capacidade do indivíduo para a realização de uma tarefa coprodutiva (ALFORD, 2002; PORTER, 2012 apud VERSCHUERE, BRANDSEN e PESTOFF, 2012). Para Alford (2002) uma maneira de ultrapassar essa barreira, contribuindo para o estímulo da coprodução, é facilitar as tarefas para o indivíduo, e para isso a tecnologia pode ser uma grande aliada. Meijer (2012 apud VERSHUERE, BRANDSEN e PESTOFF, 2012)

\footnotetext{
4 Novos modelos para administração pública vêm surgindo como resposta a esse olhar tecnicista, como Governança Pública e Novo Serviço Público. Ver mais em Bevir (2010) e Rhodes (1996) para Governança Pública e Denhardt e Denhardt (2003) para o Novo Serviço Público.
} 
também defende que a tecnologia pode ajudar no processo coprodutivo. No entanto,argumenta que isso pode depender da política em questão e da situação institucional da existência de cidadãos capazes de vincular coprodução com a tecnologia.

Embora a coprodução tenha duas atribuições principais (original: envolver o cidadão para diminuir os custos do serviço prestado; recente: envolver o cidadão buscando valores democráticos), percebe-se que, mesmo sob o olhar mais recente, são utilizadas algumas metodologias consagradas por atores que trabalharam segundo a perspectiva da coprodução original. É o caso das tipologias de Whitaker (1980) e Brudney e England (1983).

Whitaker (1980) foi o primeiro a delinear uma tipologia para a coprodução (SALM e MENEGASSO, 2010), usando como critério a forma de participação do cidadão. Para o autor, existe atividade coprodutiva quando o cidadão solicita assistência para prestação de serviço, quando coopera voluntariamente prestando o serviço junto aos agentes públicos ou, ainda, quando há interação entre cidadãos e agentes públicos com a participação ativa de ambos, ajustando suas expectativas em relação ao serviço.

Já Brudney e England (1983) definem tipos de coprodução segundo o modo de organização das pessoas. Esse modo cria uma hierarquia de atividades coprodutivas conforme seus benefícios. Essa hierarquia é estabelecida verificando-se o grau de sobreposição entre cidadãos e servidores públicos. Os tipos são:

a) coprodução individual: consiste no envolvimento individual nas atividades coprodutivas. Em geral, trata-se de um pequeno esforço coprodutivo cujos benefícios são maiores para o indivíduo do que para a sociedade;

b) coprodução de grupo: trata-se de vários cidadãos cujas atividades coprodutivas envolvem trabalho voluntário e participação ativa. Além disso, esse grupo pode requerer mecanismos de coordenação formal no relacionamento entre cidadãos e servidores públicos. O benefício, apesar de ser para um maior grupo de cidadãos, ainda se restringe a uma comunidade;

c) coprodução coletiva: é aquela em que há envolvimento de vários cidadãos, e a produção do bem ou serviço é um benefício de todos, independente de quem participe. O grau de envolvimento entre servidores públicos e cidadãos é alto assim como os benefícios que essa atividade coprodutiva gera.

Bovaird (2007), com o objetivo de tentar prever como agentes públicos e cidadãos podem interagir, cria um quadro comparativo para verificar a relação entre usuários do serviço/comunidade e os agentes públicos na prestação dos serviços públicos. O caso de total coprodução acontece quando ambos, servidores e cidadãos, interagem tanto no planejamento quanto na prestação do serviço.

A literatura mais recente de coprodução entende que esta não acontece apenas na prestação do serviço, mas também na formulação, monitoramento e avaliação desses serviços (BOVAIRD, 2007). Ribeiro, Salm e Menegasso concordam com essa visão, pois para eles, "a coprodução do bem público envolve a participação ativa e direta do cidadão nos processos de elaboração, desenho, implementação e avaliação das políticas públicas voltadas ao interesse público e, em última instância, à construção do bem comum” (2007, p. 232). Bovaird (2007) usa o exemplo brasileiro do orçamento participativo de Porto Alegre (1989) como uma experiência de coprodução em que milhares de cidadãos se envolveram nas decisões de planejamento da cidade.

Ao longo dos anos, a ideia de coprodução foi ganhando maior interesse por parte dos estudiosos da administração pública, e, sendo um tema relativamente recente, seu conceito ainda se encontra em fase de construção. Entre pesquisas teóricas e empíricas, os pesquisadores de coprodução buscam delinear um arcabouço teórico que se encarregue de produzir uma compreensão do fenômeno. 
O ideal de coprodução representa o envolvimento do cidadão (ou grupos de cidadãos), o Estado e até mesmo atores do mercado que, numa relação de confiança, compartilham responsabilidades ao produzir juntos um bem ou serviço público. Ribeiro, Salm e Menegasso (2007) agregam mais características à coprodução como: esforços coletivos, processo colaborativo, resultados que beneficiam a todos, promoção da cidadania e aprendizado coletivo. Além desses elementos valorativos que compõem a coprodução, para Nadir, Salm e Menegasso, é função da coprodução "mobilizar diversas instâncias da sociedade em torno da solução de um problema de interesse público cujo enfrentamento ultrapassa a capacidade de ação isolada do estado" (2007, p. 65).

Uma observação feita por Rocha, Spaniol, Schommer et al. (2012, p. 6) que ajuda a esclarecer o conceito é que "ao participar, o cidadão passa a acessar e a se utilizar do aparato institucional, o que permite, também, redefinir suas concepções de bem público e ampliar sua capacidade de contribuir para serviços de melhor qualidade". A coprodução do bem público, então, pode ser considerada uma estratégia. Não simplesmente uma estratégia para reduzir gastos do governo, mas, sobretudo, uma estratégia que una Estado e cidadão, fazendo com que, além de produzirem bens e serviços públicos, fomentem a democracia.

É possível, com base em alguns estudos já feitos, reconhecer algumas características básicas da coprodução. Uma delas é a existência obrigatória de dois atores-chave: o governo e a sociedade. O conceito de coprodução traz o entendimento de que a qualidade dos serviços públicos será maior se houver a participação da sociedade, em vez de o governo ser o único produtor. Assim, como afirmam Ronconi, Debetir e De Mattia (2011, p. 55), "na coprodução desaparece a concepção tradicional do Estado como núcleo exclusivo da formulação e implementação das políticas públicas; cidadãos passam a ser coprodutores e parceiros na perspectiva de compartilhamento de responsabilidades".

É vital ter em mente que a coprodução não exclui o Estado da produção do bem público. Uma barreira inicial ao conceito seria a resistência por parte de agentes públicos no compartilhamento de poder, seja porque não confiam nos outros coprodutores a ponto de lhes dar responsabilidades, seja porque simplesmente não sabem trabalhar em colaboração (BOVAIRD, 2007). Mas esse é justamente o papel da coprodução: criar uma atmosfera de confiança e compartilhamento de responsabilidade, agregando atores.

O outro ator chave do processo coprodutivo é o cidadão, desde que seu papel seja de uma participação ativa e não passiva. Em muitas definições do conceito de coprodução é possível observar essa característica da existência de participação ativa. Para Ostrom (1996, p. 1073), "coprodução implica que cidadãos podem desempenhar um papel ativo na produção de bens e serviços públicos". Para Schommer, Bueno e Kunler (2010, p. 4) é possível considerar que "um bem ou serviço público é coproduzido quando envolve a participação ativa e conjunta entre cidadãos e agentes públicos, abrangendo ou não organizações privadas associativas ou empresariais".

Brudney e England (1983, p. 59) já consideraram a importância desse papel ativo, quando conceituaram coprodução como "um conceito emergente do processo de prestação de serviços que prevê a participação direta dos cidadãos na concepção e na prestação de serviços da cidade com os agentes de serviços profissionais". Uma vez que a participação do cidadão é de importância crucial para a coprodução, Salm e Menegasso (2010), como contribuição para o debate, desenvolveram cinco modelos conforme o nível de participação dos cidadãos: 


\section{Quadro1}

\section{Modelos de coprodução do bem público a partir de tipologias de participação}

\begin{tabular}{|l|l|}
\hline $\begin{array}{l}\text { Modelos de } \\
\text { coprodução }\end{array}$ & Caracterização do modelo \\
\hline $\begin{array}{l}\text { Modelo de } \\
\text { coprodução } \\
\text { nominal }\end{array}$ & $\begin{array}{l}\text { Produção dos serviços públicos por meio do compartilhamento de } \\
\text { responsabilidades entre pessoas da comunidade, preferencialmente } \\
\text { voluntários, e o aparato administrativo público do Estado, com o propósito, } \\
\text { apenas, de tornar eficientes esses serviços. Participação: não há participação } \\
\text { efetiva e de poder do cidadão sobre o Estado. }\end{array}$ \\
\hline $\begin{array}{l}\text { Modelo de } \\
\text { coprodução } \\
\text { simbólico }\end{array}$ & $\begin{array}{l}\text { Envolvimento dos cidadãos na produção dos serviços públicos para } \\
\text { demonstrar a presença do Estado. Participação: caráter manipulativo de } \\
\text { participação. }\end{array}$ \\
\hline $\begin{array}{l}\text { Modelo de } \\
\text { coprodução } \\
\text { funcional }\end{array}$ & $\begin{array}{l}\text { Utilizado pelo aparato público do Estado para produzir os serviços públicos } \\
\text { de maneira mais eficiente e eficaz, com a participação do individuo, do grupo } \\
\text { ou da coletividade. Participação: pela solicitação dos serviços de assistência } \\
\text { ao Estado ou por um ajuste mútuo com este. }\end{array}$ \\
\hline $\begin{array}{l}\text { Modelo de } \\
\text { coprodução } \\
\text { representativa } \\
\text { com } \\
\text { sustentabilidade }\end{array}$ & $\begin{array}{l}\text { Resultado da sinergia estabelecida na realização dos serviços públicos de que } \\
\text { participam os cidadãos, as organizaçães da comunidade e o aparato } \\
\text { administrativo do Estado que, no seu conjunto, interagem em prol do bem } \\
\text { comum. Participação: interação do cidadão com o aparato administrativo do } \\
\text { Estado e da delegação de poder pelo Estado. O empowerment e a } \\
\text { accountability são essenciais, requerendo o engajamento civico do cidadão e } \\
\text { da comunidade. }\end{array}$ \\
\hline $\begin{array}{l}\text { Modelo de } \\
\text { coprodução para a } \\
\text { mobilização } \\
\text { comunitária }\end{array}$ & $\begin{array}{l}\text { Realização dos serviços públicos com a participação detoda a comunidade, } \\
\text { orientada por princípios éticos e pela democracia normativa, visando manter } \\
\text { a sociedade permanentemente mobilizada. Participação: permanente } \\
\text { mobilização da comunidade e superação da organização burocrática. }\end{array}$ \\
\hline
\end{tabular}

Fonte: Adaptado de Salm e Menegasso (2010).

Esses modelos mostram que há diferentes graus de participação do cidadão, os quais, por sua vez, definem diferentes níveis de coprodução segundo este quesito. Ao considerarmos um tipo ideal de participação, correspondendo ao modelo de coprodução para a mobilização comunitária, é possível concordar que sua prática auxilia a formulação e a implementação de políticas públicas conforme as necessidades do cidadão, além de garantir maior transparência e accountability, ampliando a confiança no governo (KLEIN, SALM, HEIDEMANN et al., 2012).

Embora durante muitos anos se tenha vinculado o conceito com o envolvimento de agentes públicos e cidadãos, hoje, há estudiosos que afirmam que ele abrange também a participação de organizações do terceiro setor. Para Brandsen e Pestoff (2006), trata-se de elevar o foco da coprodução do nível micro da sociedade para os níveis meso e macro. Eles se baseiam em Osborne e McLaughlin (2004, apud BRANDSEN e PERSTOFF, 2006) para afirmar que no Reino Unido a coprodução vem sendo usada para analisar organizações de voluntários e comunitárias no fornecimento de serviços públicos. Nas pesquisas que fizeram, Brandsen e Pestoff (2006) concluem que o envolvimento do terceiro setor transforma a prestação de 
serviço público num processo dinâmico. Pestoff (2011), em seu estudo sobre a participação dos pais nos serviços pré-escolares da Europa, observa que o terceiro setor contribui efetivamente para fomentar a coprodução, uma vez que os pais se mostraram mais dispostos a coproduzir quando aquele se envolve na prestação do serviço.

Uma vez definido que a coprodução pode ser uma grande estratégia não simplesmente para eficiência econômica do Estado, mas também como promotora da democracia e maior envolvimento da sociedade nas questões de interesse público, algumas características valorativas que provêm da coprodução podem ser identificadas. Uma delas é a confiança. Para Ribeiro, Salm e Menegasso (2007), sentimentos como confiança afloram nas trocas sociais que acontecem na coprodução. Bovaird (2007) defende que na coprodução tanto representantes da sociedade quanto do poder público assumem riscos, por isso seu relacionamento deve ser baseado na confiança de um no outro. Para este autor, a viabilidade política e prática da coprodução requer que os servidores públicos confiem mais nas decisões tomadas pelos cidadãos. Salm e Menegasso (2010) chamam atenção para a sugestão de Levine de que o Estado deve adotar mecanismos que possibilitem o envolvimento do cidadão, não por motivos econômicos, mas para que promova a confiança na administração pública. A coprodução é entendida por este autor como uma estratégia para envolver e chamar o cidadão para participar da esfera pública.Klein, Salm, Heidemann et al.(2012) concordam, acrescentando que a prática da participação possibilitada pela coprodução do bem público contribui para uma maior confiança pública no governo.

Para Schommer, Bueno e Kunzler (2010), quanto maior a confiança entre os atores, melhor será o trabalho conjunto. Os autores, contudo, ressalvam que uma maior confiança não elimina os conflitos nem a diversidade de opiniões, pois possibilita um ambiente democrático, ao qual se adiciona uma relação de confiança, resultando num terreno fértil para a construção de redes. As redes, por sua vez, vêm se tornando cada vez mais relevantes já que são uma forma de administrar políticas e projetos que envolvem problemas complexos, recursos escassos, diversos atores e a interação de agentes públicos e privados (RONCONI, 2008). Elas também favorecem a horizontalidade, cabendo observar que, conforme argumenta Ostrom (1996), a sinergia entre governo e cidadãos acontece quando há relações horizontais entre esses atores e que o sucesso da coprodução depende justamente disso.

Nessa perspectiva, alguns autores estabelecem forte relação entre os conceitos de coprodução e redes, conforme se percebe em Schommer, Andion, Pinheiro et al. (2011, p. 40): “entende-se produção do bem público como estratégias de produção de bens e serviços públicos em redes e parcerias, contando com engajamento mútuo de governos e cidadãos, individualmente ou em torno de organizações associativas ou econômicas".

A coprodução pressupõe a formação de redes quando o envolvimento dos diversos atores é tal que há conflito de interesses, mas também há valores compartilhados que vão além de objetivos particulares, o que predispõe negociação e ajuste dos interesses a favor de um bem comum (KISSLER e HEIDEMANN, 2006; RONCONI, 2008).

Outra característica indissociável do conceito de coprodução é a da responsabilidade compartilhada. Na coprodução, o envolvimento de dois ou três setores (Estado e mercado, Estado e sociedade ou Estado, mercado e sociedade) gera uma expectativa entre esses atores sobre a quem cabe, afinal, a responsabilidade pelos resultados da produção do bem público. Os estudiosos entendem que ela deve ser de todos os coprodutores, pois na relação entre os atores do Estado e da sociedade na produção do bem público há riscos, como mencionado por Bovaird (2007). Como afirmam Schommer, Andion, Pinheiro et al. (2011, p. 40) "a coprodução pressupõe práticas compartilhadas (que tornam os cidadãos) corresponsáveis pelas políticas públicas". Esse comprometimento pressupõe um envolvimento do cidadão nas questões de interesse público;tendo-se em conta a sua decisão subjetiva de participar.

Um tema bastante estudado por pesquisadores de administração pública é a questão da accountability. No caso da coprodução do bem público que valoriza aspectos democráticos, de participação e responsabilidades, 
ela se tornou um elemento fundamental. No entanto, para entender essa perspectiva na coprodução é preciso seguir a sugestão de Denhardt (2012, p. 267) e reconhecer que "accountability não é simples". No caso do Brasil, o problema é ainda maior ao se verificar, conforme constatou Pinho e Sacramento (2009), que o termo não existia no país até o final do século XX. Nesse sentido, não se trata apenas de não possuir uma tradução da palavra em português, mas também de não existir uma cultura de accountability no país (CAMPOS, 1990).

Ana Maria Campos, ao publicar em 1990 “Accountability: quando poderemos traduzí-la para o português?”, trouxe a questão à tona no Brasil. Passados vinte anos, Pinho e Sacramento (2009) perguntaram se "já podemos traduzi-la para o português", e apesar de não haver uma resposta definitiva, esses autores mostram os avanços do país em direção à accountability.

Outros autores chegaram à mesma conclusão, como Rocha, Spaniol, Schommer et al. (2012), que a veem como uma categoria político-cultural dificultada pela relação histórica entre Estado e sociedade e pela frágil cultura política no país. Nessa mesma direção caminham as práticas de coprodução no país, e para alguns autores os conceitos de coprodução e accountability, embora sempre em fase de construção, estão interrelacionados, conforme constatam Schommer, Bueno e Kunzler (2010, p.5):

Ao envolver corresponsabilização pelo processo e pelos resultados, o conceito de coprodução relaciona-se com o debate sobre accountability, não apenas no sentido do acesso a população a informações sobre os serviços e oportunidades e canais para questioná-las, mas principalmente porque exige a responsabilização contínua dos envolvidos nas decisões e na execução dos serviços.

Rocha, Spaniol, Schommer et al. (2012, p. 5) afirmam que a produção de informações confiáveis é essencial para a accountability, ao mesmo tempo em que essa produção é um desafio que "depende da ação de órgãos e mecanismos de controle estatais e de mecanismos de controle social, os quais podem interagir entre si em maior ou menor grau". Os autores concluem que é justificável, então, fazer a coprodução do controle para promover a accountability. Pode-se, assim, constatar que coprodução e accountability se promovem mutuamente. Bovaird (2007), no entanto, alerta que a coprodução pode, na verdade, diluir a accountability pública por conta das divisões de poder, autoridade e controle entre o Estado e os grupos de cidadãos.

Em resumo, pode-se compreender a coprodução do bem público como uma estratégia que nasceu para, além de reduzir gastos do governo, melhorar a qualidade dos serviços públicos com a contribuição de seus usuários/cidadãos. Nos últimos anos esse conceito tem se ampliado, visando unir atores do governo e da sociedade que, para além de produzir bens e serviços públicos, fomentem valores democráticos. A partir disso, os estudiosos constataram, sobretudo por meio de estudos de caso, que com a coprodução é possível caminhar para uma abordagem mais humanizada da administração pública, resgatando um aspecto político do interesse público. Assim, são vislumbradas algumas características da coprodução, tais como participação de atores do governo que compartilham experiências, conhecimento e poder com coprodutores; participação ativa (e não passiva) de atores da sociedade, sejam eles cidadãos, grupos de cidadãos e/ou terceiro setor; confiança na relação entre esses atores; criação de redes de coprodução; o compartilhamento de responsabilidades e a accountability.

\section{A Ética da Discussão em Habermas}

Jürgen Habermas, filósofo alemão nascido em 1929, é sem dúvida nenhuma, um dos pensadores mais discutidos e comentados do século XX. Como não é objetivo deste artigo recuperar sua trajetória intelectual, cumpre apresentar os principais elementos de seu pensamento no campo da moral e da ética, em relação à qual, segundo Dutra (2002), suas preocupações foram determinar o sentido de enunciados normativos e a 
possibilidade de sua formulação. Além disso, é relevante trabalhar com seu conceito de democracia, pois o mesmo tem relação estreita com sua reflexão ética e pode ser relacionado à coprodução.

Dupeyrix (2012) afirma que, para Habermas, é possível distinguir duas formas de racionalidade: a instrumental e a moral prática ou discursiva. O primeiro tipo é baseado num paradigma de conhecimento científico que aciona uma relação sujeito-objeto e gera um saber materializante em que o objetivo é utilizar e tirar proveito do conhecimento. Schneider e Ingram (1997) a definem como aquela em que os melhores meios disponíveis são utilizados para se alcançar metas objetivamente definidas. No entanto, ressalvam que tal racionalidade é desumanizadora e prejudicial às crenças morais e filosóficas da sociedade, colocando obstáculos à democracia ao criar uma sociedade hierárquica onde os especialistas predominam. De acordo com Vizeu (2006), essa racionalidade se materializa em ações estratégicas, objetivas e não dialógicas.

Já a racionalidade discursiva encontra seu lugar na comunicação e busca estabelecer o entendimento, a partilha e a cooperação. Ela possibilita que as questões morais sejam construídas e abordadas pela linguagem, permitindo ainda que sejam tratadas racionalmente, sendo por isso necessária a construção de uma ética da discussão (DUPEYRIX, 2012). A racionalidade discursiva ou comunicativa se refere à tentativa de atingir o entendimento entre pessoas que buscam compreender umas às outras, em vez de se controlarem ou dominarem. Como se conclui a partir de Vizeu (2009), em Habermas, a linguagem permite conferir significado ao mundo em que se vive, e este significado permite orientar as ações. Logo, pode-se aferir que a ação moral depende do que se quer dizer com "moral" (SCHNEIDER e INGRAM, 1997). É uma ação que satisfaz os critérios de validade propostos por Habermas (conforme SCHNEIDER e INGRAM, 1997;VIZEU, 2005), ou seja, verdade proposicional, retidão, sinceridade e inteligibilidade. Pegoraro (2006) considera que a ética da discussão (ou discursiva) pode ser sintetizada na construção de um "ponto de vista moral" em que seja possível realizar um juízo ético universal e imparcial.

Dupeyrix (2012) afirma que nessa ética Habermas pressupõe que deve haver uma simetria entre o interlocutor e o locutor, que se respeitam mutuamente e se reconhecem como pessoas responsáveis, além de se descentrarem de seus interesses. Sobre esse último ponto de vista, Habermas (1999) afirma que não apenas é preciso generalizar normas e máximas, mas também que os interlocutores abandonem o contexto social e histórico em que vivem (e o de suas comunidades), adotando o ponto de vista de todos os indivíduos potencialmente afetados. Ainda assim, é preciso considerar questões como as distorções comunicativas (VIZEU, 2009), cuja origem possivelmente está na predominância de uma racionalidade econômica nas relações entre os membros da comunidade linguística. Essa predominância pode decorrer da motivação dos agentes, da veracidade do que é dito (no caso da fala ser baseada em conhecimentos falsos), da falta de legitimidade ou da própria falta de clareza na comunicação. Nas palavras do próprio Habermas (2007), a ordem moral definida pela ética da discussão ou discursiva possui um teor de respeito indistinto e de responsabilidade com cada pessoa. Para construí-la, os interlocutores estariam em uma situação ideal de palavra, na qual esses pressupostos se verificam e da qual Habermas extrai dois princípios:

a) princípio D (discussão): a norma será válida se todas as pessoas que podem estar envolvida concordam ou podem concordar com ela enquanto participarem de uma discussão prática sobre sua validade;

b) princípio U (universalidade): a norma válida deve satisfazer à condição de que suas consequências e efeitos colaterais para a satisfação dos interesses de cada um, resultantes da sua observação por todos, possam ser aceitas por todas as pessoas envolvidas (DUPEYRIX, 2012; HABERMAS, 1989).

Para Dupeyrix (2012), os princípios D e U permitem distinguir as normas válidas das não válidas. Enquanto U é um princípio de argumentação, $\mathrm{D}$ estabelece o vínculo entre a racionalidade moral e a discussão prática. O princípio U, de acordo com Pegoraro (2006) representa um consenso universal construído a partir do debate argumentativo livre entre todos os participantes, não uma norma fixa e suprema. Por sua vez, o princípio D permite resolver por meio da discussão (e imparcialmente) os eventuais conflitos de interesse que possam ocorrer dentro de uma sociedade, a partir das normas éticas existentes. Rouanet (1989) observa: 
o princípio U permite fundamentar discursos práticos, pois cada pessoa que se engaja em uma discussão livre está obrigada a observá-lo, o que implica admitir que, na discussão moral, todos os interesses devem ser debatidos, sendo ilegítimo excluir quaisquer deles, bem como é injustificável coagir ou excluir participantes, vedando-lhes ou cerceando-lhes o acesso ao debate. Assim, os princípios não somente fornecem regras para o processo, mas também produzem sua legitimidade.

Habermas (2007) afirma que a ordem moral não deve ser considerada suposta, pois é construída pelos agentes racionais que discutem. Ela se caracteriza por ser deontológica (pois se apoia em normas), cognitivista (sua precisão normativa é um objeto do conhecimento), formalista (produzida por meio de procedimentos, em que, antes de se interessar pelo conteúdo da norma, o analista deve verificar até que ponto ela foi produzida corretamente) e universalista porque deve obter o acordo de todos os que participaram de sua formulação (DUPEYRIX, 2012). Entretanto, como observou Vizeu (2009), é preciso que se entenda que as palavras e os conceitos fazem sentido em uma determinada comunidade linguística cujos membros compartilham do mesmo significado, o que leva à conclusão de que uma regra moral não pode ser "exportada" de uma comunidade para outra, a menos que ambas concordem com seu significado. Para Dutra (2002), o cognitivismo e o formalismo próprios da ética da discussão apontam para o reconhecimento de que esta não propõe normas positivas, e sim define os procedimentos e métodos que as criem e justifiquem: cada sociedade, em cada momento histórico, produz as normas morais que julga aplicáveis a sua realidade. Pegoraro (2006) reforça esse ponto de vista ao afirmar que a ética discursiva não trata dos pontos de vista morais normalmente aceitos em uma sociedade.

Habermas (1989; 1999) utiliza a perspectiva do desenvolvimento moral construída pelo psicólogo cognitivista Lawrence Kohlberg, que distinguiu três níveis e seis estágios nesse desenvolvimento, conforme o quadro2 a seguir:

\section{Quadro 2}

\section{O desenvolvimento moral}

\begin{tabular}{|l|l|}
\hline \multirow{2}{*}{ Nível } & Estágio \\
\hline \multirow{3}{*}{ Convencional } & 1. punição e obediência \\
\cline { 2 - 3 } & 2. projeto instrumental individual e de permuta \\
\hline \multirow{3}{*}{ Pós-convencional } & $\begin{array}{l}\text { 3. expectativas interpessoais e mútuas, relações e } \\
\text { conformidade }\end{array}$ \\
\cline { 2 - 2 } & 4. manutenção da consciência e do sistema social \\
\hline & $\begin{array}{l}\text { 5. primeiros direitos, contrato social ou utilidade } \\
\text { social }\end{array}$ \\
\cline { 2 - 2 } & 6. princípios éticos universais \\
\hline
\end{tabular}

Fonte: Dupeyrix (2012, p. 59).

De acordo com Dupeyrix (2012), o nível pós-convencional é o que interessa a Habermas, pois permitiria reconstruir as normas da vida social a partir da perspectiva moral que ele defende, bem como analisar criticamente as sociedades existentes. Desse modo, seriam criadas as condições para deixar de lado as perspectivas egoístas e autocentradas que as norteiam, o que se conseguiria pelo aprendizado e o desenvolvimento moral,sendo assim estabelecidas as normas universais que organizariam todo o 
mundo.Além disso, nesse nível, seria possível despertar (através do princípio U) interesses gerais ou generalizáveis que, segundo Dutra (2002), devem ser considerados como aqueles passíveis de universalização.Se for considerado que os juízos morais, conforme Habermas (1999), são fundamentados nas regras morais e produzem a obrigação de um determinado comportamento, tem-se que no estágio pósconvencional as pessoas sejam capazes de aplicar regras e normas morais em ações que visariam ao interesse coletivo. É importante observar ainda, como faz Pegoraro, que as teorias do bem e da justiça, para Habermas, não devem ser consideradas opostas nem tampouco concorrentes, devendo cada uma delas desempenhar um papel na vida social:

[...] a justiça legal em nada se opõe ao bem quando critica os modelos abstratos e universalistas justamente para manter um horizonte geral que possa garantir a validade do discurso particular sobre o bem e o destino das pessoas e das comunidades particulares. (PEGORARO, 2006, p. 137)

De especial interesse é a visão habermasiana de democracia. Como observa Dupeyrix (2012), Habermas trabalha com a perspectiva de que as normas sociais devem ser submetidas a um teste de moralidade que verifique se são universais e racionais. Para tanto, precisam ser submetidas à deliberação discursiva, formando, assim, um modelo de democracia procedimental. Em seu ensaio "Três modelos normativos de democracia", Habermas (2007) reconhece dois modelos e propõe o seu próprio, que podem ser descritos como segue:

a) modelo "liberal": o processo democrático é utilizado para "programar" o Estado, compreendido como aparato de administração pública, para que atenda ao interesse da sociedade, visualizada com um sistema de circulação de pessoas em particular e de seu trabalho estruturado conforme as leis do mercado. Um aparato estatal de uso do poder político deve conjugar e impor os interesses sociais conforme os fins coletivos;

b) modelo "republicano": a política possui uma função coletivizante e deve ser vista como uma reflexão sobre uma forma ética de vida pela qual os indivíduos se conscientizam de sua interdependência, formando relações de reconhecimento mútuo e se percebendo como livres e iguais. A solidariedade é uma forma de integração social, tanto quanto o poder administrativo do Estado e o interesse próprio do mercado. A formação da opinião pública deve seguir um paradigma de interlocução. No entanto, os compromissos em torno dos interesses a serem promovidos dependem de ações estratégicas, em vez de um discurso racional capaz de neutralizar o poder;

c) modelo procedimental: uma política deliberativa permite incorporar diferentes discursos- sobretudo, de grupos marginalizados- que vão contra os consensos da maioria da sociedade, mas que precisam ser compensados de alguma forma. Deve-se buscar um equilíbrio entre os interesses divergentes e conseguir um acordo e uma fundamentação moral. Assim, condições adequadas de comunicação e procedimentais devem estar disponíveis para que se possa formar a vontade e as opiniões, sendo essas condições de comunicação a base do terceiro modelo de democracia. Este incorpora elementos dos modelos anteriores, de modo a garantir coesão interna entre negociações, discursos sobre a justiça e de autoentendimento. A política democrática exige auto-organização da sociedade, fazendo com que o Estado (como aparato de administração pública) não seja o promotor do bem-estar da sociedade. 


\section{Ética da Discussão e Coprodução: as Possibilidades de Diálogo}

O conceito de coprodução, como visto em seção anterior,tangencia diferentes dimensões da vida humana em sociedade para propor uma nova forma de produzir o bem público, compreendendo necessariamente a participação do cidadão e a mobilização de suas energias para esse fim. Um diálogo entre o conceito e a ética se faz necessário, haja vista que se trata de um empreendimento coletivo, em que as relações entre os seres humanos envolvidos devem ser pensadas e descritas a partir de motivações para sua construção - e a ética pode fornecer uma dessas motivações, que será explorada aqui.

Em primeiro lugar, percebe-se que a coprodução é compreendida no plano teórico como um processo. Não há uma definição prévia de bem público a ser produzido através desse modelo, e, sim, a preocupação de que ela possa gerar, por meio da participação e do envolvimento, os bens e serviços que satisfaçam às necessidades da população. Da mesma maneira, Habermas entende que a ética da discussão não serve para validar normas morais existentes, e sim produzir aquelas que possam nortear a vida em sociedade a partir da discussão sobre como as pessoas devem viver. Dessa forma, no plano teórico, ambos os modelos são basicamente procedimentais.

Em seguida, é preciso mencionar a contribuição de Alford (2002) ao observar que a motivação para a coprodução não provém somente da busca pelo interesse próprio, pois a socialização e a promoção de valores se mostram motivações para a ação bastante importantes para o funcionamento do modelo. Isto é, percebe-se, nessa concepção, que a coprodução representa uma estratégia de produção do bem público em que a promoção dos interesses pessoais é apenas uma das razões para uma pessoa se envolver. Da mesma forma, observa-se que o contato com outras pessoas, a possibilidade de comparar seus pontos de vista e seus interesses com elas, bem como a busca por um consenso em relação aos valores a serem promovidos na sociedade, desempenham papel importante no engajamento nessa prática. Ora, esse contato precisa do reconhecimento, como observou Habermas, de que o outro agente envolvido é um ser humano racional, capaz de expressar e debater seus pontos de vista e defender seus valores. É possível, também, observar que a correta motivação na coprodução (isto é, a produção de um bem público e não do bem particular) pode reduzir, na construção desse processo, os riscos de uma distorção comunicativa,tal como apontado por Vizeu (2009).

A coprodução, conforme se entende aqui, deve se processar no que Habermas chama de "mundo da vida". Esse mundo pode ser descrito, segundo Queirós (2011), como o cotidiano da sociedade civil, diferenciado dos subsistemas econômico e político, em que o dinheiro e o poder dão as cartas. Entretanto, há uma dificuldade muito grande em conseguir dissociar a produção do bem público, empiricamente, de ambos os subsistemas: embora o interesse na coprodução deva ser o coletivo, é muito difícil evitar o surgimento de interesses privados. Na situação ideal da ética discursiva, em que os agentes envolvidos na discussão são racionais, capazes de compreender e argumentar, e participam do debate em situação de igualdade com os demais, seria possível supor que todos estão aptos a discernir entre o que serve aos interesses do subsistema do dinheiro e ao do poder. Isso, no entanto, conforme já observado, trata-se de um ideal. Pode-se afirmar que o conceito de coprodução depende de uma cidadania deliberativa, que Habermas construiu em 1995 e Tenório (1998) já definia como uma cidadania que adota um procedimento democrático e deliberativo em que se pode construir destinos sociais.

A preocupação de Habermas de que a norma moral seja definida a partir da comunicação, da interação e da discussão entre todos os agentes racionais na sociedade para que possa ser considerada válida pode ser comparada com a perspectiva da coprodução. A tipologia de Brudney e England (1983), em que se progride de uma perspectiva individual para a coletiva, mostra-se bastante interessante nesse sentido. Os autores consideram necessário envolver, aqui, vários cidadãos na busca da produção de um bem ou serviço que beneficie a todos; da mesma forma, a norma moral produzida pela ética da discussão deve ser aplicável a todos na sociedade. Schneider e Ingram (1997) demonstram como os critérios de validade podem ser adaptados para um ambiente institucional, de modo que o uso da ação comunicativa em escala social na coprodução não se torne um problema. Além disso, como demonstra a complementação feita por Bovaird 
(2007) à tipologia, uma coprodução total exige a interação entre servidores e cidadãos não apenas na produção, mas também no planejamento, indicando aqui um grau elevado de abertura para a participação. Este, por sua vez, implica reconhecer que a coprodução exige interações bastante profundas entre os sujeitos envolvidos. Implica admitir que a discussão entre esses sujeitos pode seguir regras de liberdade e inclusão como as que Habermas preconiza em sua situação ideal de fala, como a simetria entre os interlocutores e o reconhecimento e respeito mútuos.

Essa proposição, entretanto, padece de um problema sério. Enquanto Habermas exige que todos os que possam ser afetados na sociedade participem, os autores que tratam da coprodução não defendem o envolvimento de toda a população. Assim, estamos diante de uma situação não ideal: ou se admite que somente uma parcela da população irá efetivamente se envolver na discussão sobre como prestar os serviços públicos - o que seria suficiente para os teóricos da coprodução (mas não para satisfazer as condições de Habermas)-, ou se abandona as pretensões envolvidas nos princípios D e U. Como uma solução para o problema, pode-se propor que as estruturas de produção de bens e serviços públicos que utilizam o modelo da coprodução fomentem e estimulem o máximo possível de participação, abrindo a possibilidade para que todos os cidadãos se envolvam, pavimentando o caminho para a satisfação da condição imposta por Habermas. É essencial, portanto, que a possibilidade de participação dos diferentes cidadãos - que possam, de uma forma ou de outra, ser afetados pela provisão do bem ou serviço público - seja compatível com estes. Assim seriam criadas condições para que o processo se aproxime dos procedimentos habermasianos.

A teoria da coprodução enfatiza o papel do cidadão individual na produção do bem público. Em princípio, a ética da discussão se fundamenta na participação desses cidadãos em um debate cujo produto deve ser a satisfação de interesses coletivos. Rouanet (1989) afirma que essa ética não é individualista, pois os seres humanos estão ocupando um espaço (o mundo da vida) intersubjetivamente compartilhado, o que, entretanto, não implica uma tutela do indivíduo pela comunidade. A interação entre os indivíduos pressupõe o reconhecimento da dignidade e da integridade de cada um. Além disso, seus direitos individuais (que, segundo Rouanet, não devem ser considerados simplesmente como direitos de cidadania, mas também como direitos humanos, em geral) não podem ser cancelados ou substituídos por direitos da comunidade. Tenório, Villela, Dias et al. (2008) afirmam que a cidadania deliberativa, moldada a partir da obra de Habermas, legitima as decisões políticas a partir de processos de discussão orientados pela inclusão, a igualdade participativa, a autonomia, o pluralismo e o bem comum. Uma vez garantidos esses princípios, encontra-se terreno fértil para a coprodução.

Isto posto, a ética da discussão manda um recado claro aos estudiosos da coprodução: embora as decisões de produção do bem público sejam coletivas e tomadas por conjuntos de cidadãos, essas decisões não podem ameaçar os direitos individuais, nem pressupor uma precedência a priori dos anseios da comunidade sobre os individuais. Em outras palavras, não se pode alcançar o bem da coletividade ao custo do bem individual.

Outro elemento que pode ser trabalhado na associação entre a coprodução e o pensamento de Habermas está na relação com a democracia. Como mencionado anteriormente, a visão original da coprodução enfatizava a redução de custos que esta poderia promover no setor público, mas os modelos mais recentes trabalham com a perspectiva de envolver os cidadãos em procedimentos democráticos. Habermas propunha um conceito mais profundo de democracia do que os modelos clássicos (liberal e republicano), em que diferentes discursos podem ser incorporados, especialmente, no que tange aos grupos sociais marginalizados.

Em princípio, essa ideia poderia ser incorporada ao conceito de coprodução sem maiores dificuldades, posto que este pode perfeitamente conviver com a perspectiva de envolver o máximo possível de cidadãos e grupos de cidadãos no processo de produção. Habermas, de acordo com Consani (2010), manifesta seu temor de que, num modelo deliberativo, os direitos fundamentais do indivíduo poderiam ser ameaçados. Entretanto, no momento em que esses direitos sejam considerados garantidores do exercício das liberdades comunicativas, esse problema desaparece. Apesar de tal garantia ser útil para o modelo de coprodução, há um fator que limita o diálogo entre esta e a democracia procedimental: o papel previsto para o aparato estatal. 
O modelo procedimental de democracia defendido por Habermas não parece de todo adequado para a coprodução, uma vez que ele parece incorporar uma superação do Estado como produtor do bem na sociedade (Habermas [2007] chega a falar em uma política contra o Estado como uma resultante desse modelo). Assim, no que diz respeito à aplicação do modelo habermasiano à coprodução, as possibilidades de diálogo com sua teoria da democracia estão prejudicadas. No entanto, isso não significa descartar completamente esse modelo, pois pode ser interessante incorporar algumas de suas características à ideia de coprodução, como, por exemplo, a participação de diferentes agentes sociais na formação de uma vontade coletiva. Nesse sentido, a discussão em torno da democracia deliberativa pode ser útil e relevante, já tendo sido, inclusive, debatida no seio de uma administração pública modificada.

Por exemplo, Paula (2005) vê na moderna visão participativa de democracia (a democracia deliberativa), diretamente influenciada pelo pensamento habermasiano, uma forma de incorporar a participação da sociedade civil na regulação da vida coletiva, em que a esfera pública é concebida como uma arena aberta à discussão, em um processo dialógico, dos diferentes grupos sociais. Nessa esfera, o uso público da razão, conforme Tenório (apud PAULA, 2005) exige condições sociais e arranjos institucionais que permitam um diálogo livre e aberto entre os cidadãos. As relações com o modelo habermasiano são evidentes, indicando que seu pensamento sobre a democracia pode ser incorporado a uma perspectiva de participação e deliberação democráticas que permitam ao aparato administrativo do Estado prestar serviços e produzir o bem público de acordo com as efetivas demandas e necessidades da sociedade. Consani (2010) vê nas teorias da democracia deliberativa a possibilidade de conciliar a soberania popular com os direitos individuais, os interesses individuais de mercado e a participação política visando ao interesse coletivo.

A coprodução tende a ganhar bastante se a lógica proposta por Tenório (1998) para a gestão social for incorporada. De acordo com este autor, a gestão social se efetivará quando os governos adotarem políticas públicas que não se refiram ao cidadão como uma meta, um cliente ou um resultado, mas como participante ativo no processo de sua elaboração. Isto é, o aspecto procedimental da ética e da democracia se preserva e pode ser adaptado à lógica da coprodução.

Para viabilizá-la, acredita-se ser fundamental construir o que Vizeu (2006) chama de espaços de participação direta do cidadão. Estes devem articular a cidadania em torno de uma noção de produção do bem comum, em que a interação entre a sociedade civil, os subsistemas político e econômico se dê de forma a satisfazer interesses coletivos, em vez de privados. Ou seja, em que a ação estratégica seja substituída por uma ação coletiva informada pelo consenso discursivamente construído. Além disso, critérios como os expostos por Tenório, Villela, Dias et al. (2008) podem ser adaptados para analisar e compreender processos de coprodução.

Finalmente, cabe discutir até que ponto a coprodução seria um processo legítimo de prestação de serviços públicos. Sua adoção em uma comunidade democrática exigiria a participação dos interessados em tais serviços tanto quanto daqueles que, mesmo não se beneficiando diretamente dos mesmos, podem ser afetados pela sua disponibilidade. Nem todos os serviços públicos produzem o bem para todos os cidadãos; ou seja, nem todos poderiam ser considerados universalmente bons no que diz respeito à satisfação das necessidades individuais. Entretanto, mesmo que um serviço não seja consumido por um determinado indivíduo, nada impede que este o considere necessário e relevante para o bem-estar social. Por exemplo, uma pessoa que não seja beneficiária de uma política de cotas para o ingresso no ensino superior público pode argumentar favoravelmente a respeito de sua instituição por considerá-la justa ou necessária para o bem-estar social. Da mesma forma, uma pessoa pode ter opiniões contrárias e desejar discuti-las quando do debate sobre a implantação de tal política.

$\mathrm{O}$ aspecto fundamental reside em não excluir tais pessoas do processo público de deliberação em torno da oferta, ou não, do serviço público em tais bases. Tal discussão, racionalmente conduzida dentro dos pressupostos defendidos por Habermas, pode levar ao consenso quanto à adoção da política de cotas, mesmo que ela não satisfaça direitos individuais específicos. Na verdadeira coprodução, o bem público é decidido consensualmente e não imposto. 


\section{Considerações Finais}

Neste artigo, procurou-se, em primeiro lugar, traçar um conceito de coprodução a partir da recuperação de sua evolução histórica e da definição de suas características. Resta demonstrado, por meio desses elementos, que a coprodução consiste numa forma de prestação de serviços públicos que estimula e fomenta a participação de agentes sociais, de cidadãos, num processo democrático, participativo e deliberativo em que diferentes interesses precisam ser debatidos e considerados dentro do quadro mais amplo do bem de uma coletividade. Portanto, a coprodução precisa ser vista como um processo. Embasada na comunicação e no debate, a coprodução deve ser resguardada de distorções comunicativas, motivo pela qual deve ser trabalhada em um contexto de igualdade, em que o poder público se envolva por meio de servidores e funcionários aptos à construção colaborativa do bem público, e em que as empresas de mercado se envolvam somente naquilo em que possam efetivamente servir às necessidades e interesses de uma coletividade.

O processo de coprodução envolve a interação entre os indivíduos e, portanto, precisa de regras éticas que o norteiem e o limitem, estabelecendo condições ideais de participação e envolvimento das pessoas. Propôs-se aqui que essas regras éticas sigam a formulação de Habermas e que a ética da discussão seja a bússola a orientar os esforços de coprodução do bem público. Justifica-se tal escolha pelo fato de tal ética ser voltada para a promoção de normas gerais através da discussão livre entre indivíduos racionais, que se reconhecem mutuamente como tais e se engajam livremente no debate sobre regras morais válidas para todos - o que, evidentemente, induz a considerá-las como de acordo com os interesses dos agentes. Da mesma maneira, os serviços públicos devem ser produzidos no interesse de todos, contemplando as necessidades de cada um. Finalmente, ao seguir uma racionalidade comunicativa e ao romper a racionalidade instrumental, ela emancipa o cidadão (TENÓRIO, 2009), condição fundamental para sua efetiva participação em um processo voltado para produzir autêntico bem público

Ademais, a formulação habermasiana produz uma visão de democracia deliberativa que se ajusta ao processo de coprodução. $\mathrm{O}$ engajamento dos cidadãos no debate e no processo de tomada de decisão sobre os bens a serem produzidos, sua distribuição e utilização por todos na coletividade, deve seguir regras que podem ser deduzidas ou adaptadas dos princípios da discussão (D) e universalização (U) propostos pelo filósofo alemão. Assim, não apenas se dispõe de regras práticas, como também de critérios de legitimação dos resultados, facilitando a tarefa dos cidadãos e agentes públicos envolvidos na coprodução.

Evidentemente, existem aspectos a serem considerados nessa questão, pois o modelo de Habermas não está isento de críticas. Não há, entretanto, espaço neste estudo para lidar adequadamente com elas. Assim, devem ser consideradas as principais contribuições deste artigo a proposição de um campo de estudos e, também, a definição de uma ideia a ser debatida e avaliada por uma comunidade de acadêmicos e profissionais da administração pública que estejam interessados em viabilizar o modelo da coprodução como estratégia de produção do bem público numa comunidade democraticamente organizada.

\section{Referências}

ALFORD, J. Why do public-sector clients coproduce? Toward a Contingency Theory. Administration \& Society, v. 34, n. 1, p. 32-56, Mar. 2002.

BEVIR, M. Democratic governance. New Jersey: Princeton, 2010.

BOVAIRD, T. Beyond engagement and participation: user and community coproduction of public service. Public Administration Review, v. 67, n. 5, p. 846-860, Sept./Oct. 2007.

BRANDSEN, T.; PESTOFF, V. Co-production, the third sector and the delivery of public services: an introduction. Public Management Review, v. 8, n. 4, p. 493-501, Oct./Dec., 2006. 
BRUDneY, J. L.; ENGLAND, R. E. Toward a definition of the coproduction concept. Public Administration Review, v. 43, n. 1, p. 59-65, 1983.

CAMPOS, A. M. Accountability: quando poderemos traduzi-la para o português? Rev. Adm. Pública, Rio de Janeiro, v. 24, n. 2, p. 30-50, Fev./Abr. 1990.

CONSANI, C. M. Teorias da democracia deliberativa: propostas e problemas. Peri, Florianópolis, v. 2, n. 1, p. 1-11, 2010 .

DENHARDT, J. V.; DENHARDT, R. B. The new public service: serving, not steering. New York: M. E. Sharpe, 2003.

DENHARDT, R. B. Teorias da administração pública. São Paulo: Cengage Learning, 2012.

DUPEYRIX, A. Compreender Habermas. São Paulo: Edições Loyola, 2012.

DUTRA, D. V. Kant e Habermas: a reformulação discursiva da moral kantiana. Caxias do Sul: Edipucs, 2002.

HABERMAS, J. Consciência moral e agir comunicativo. Rio de Janeiro: Tempo Brasileiro, 1989.

. Três modelos normativos de democracia. Lua Nova, São Paulo, n. 36, p. 39-53, 1995.

. Comentários à ética do discurso. Lisboa: Instituto Piaget, 1999.

. A inclusão do outro. São Paulo: Edições Loyola, 2007.

KLEIN, V. H. et al. Participação e coprodução em política habitacional: estudo de um programa de construção de moradias em SC. Rev. Adm. Pública, v. 46, n. 1, p. 25-48, 2012.

KISSLER, L.; HEIDEMANN, F. G. Governança púbica: Novo modelo regulatório para as relações entre Estado, Mercado e Sociedade. Rev. Adm. Pública, Rio de Janeiro, v. 40, n. 3, p. 479-99, Mai./Jun., 2006.

NADIR JR., A. M.; SALM, J. F.; MENEGASSO, M. E. Estratégias e ações para a implementação do ICMS ecológico por meio da coprodução do bem público. Revista de Negócios, Blumenau, v. 12, n. 3, p. 62-73, Jul./Set. 2007.

OSTROM, E. Crossing the great divide: coproduction, synergy, and development. World Development, v. 24, n. 6, p. 1073-1087, 1996.

PAULA, A. P. P. de. Por uma nova administração pública. Rio de Janeiro: FGV, 2005.

PEGORARO, O. Ética dos maiores mestres através da história. Petrópolis: Vozes, 2006.

PESTOFF, V. Co-production, new public governance and third sector social services in Europe. Ciências Sociais Unisinos, v. 47, n. 1, p. 15-24, Jan./Abr. 2011.

PINHO, J. A. G. de; SACRAMENTO, A. R. S. Accountability: já podemos traduzi-la para o português? Rev. Adm. Pública, v. 43, n. 6, p. 1343-68, Nov./Dez. 2009.

QUEIRÓS, R. P. de. A esfera pública como elemento central da democracia deliberativa. Fides, Natal, v. 2, n. 2, p. 23 40, Jul./Dez. 2011.

RHODES, R. A. W. The new governance: governing without government. Political Studies, Newcastle, n. 44, p. 652667,1996

RIBEIRO, R. M.; SALM, J. F.; MENEGASSO, M. E. Coprodução do bem público e o desenvolvimento da cidadania: o caso do PROERD em Santa Catarina. Revista Alcance, v. 14, n. 2, p. 231-246, Maio/Ago. 2007.

ROCHA, A. C. et al. A coprodução do controle do bem público essencial à Accountability. In: ENCONTRO CIENTÍFICO DE ADMINISTRAÇÃ̃ DA ASSOCIAÇÃO NACIONAL DE PÓS-GRADUAÇÃO E PESQUISA EM ADMINISTRAÇÃO - ENANPAD, 26. 2010. Rio de Janeiro. Anais... Rio de Janeiro: ANPAD, 2012. CD-ROM. 
RONCONI, L. F. A. A Secretaria Nacional de Economia Solidária:uma experiência de governança pública. 2008. 279 f. Tese (Doutorado em Sociologia Política) - Universidade Federal de Santa Catarina, Florianópolis, Santa Catarina, 2008.

; DEBETIR, E.; DE MATTIA, C. Conselhos gestores de políticas públicas - potenciais espaços para a coprodução dos serviços públicos. Contabilidade, Gestão e Governança, Brasília, v. 14, n. 3, p. 46-59, Set./Dez. 2011.

ROUANET, S. P. Ética iluminista e ética discursiva. Tempo Brasileiro, v. 98, p. 23-78, 1989.

SALM, J. F.; MENEGASSO, M. E. Proposta de modelos para a coprodução do bem público a partir das tipologias de participação.In: ENCONTRO CIENTÍFICO DE ADMINISTRAÇÃO DA ASSOCIAÇÃO NACIONAL DE PÓSGRADUAÇÃO E PESQUISA EM ADMINISTRAÇÃO - ENANPAD, 24., 2010, Rio de Janeiro. Anais... Rio de Janeiro: ANPAD, 2010. CD-ROM.

SCHNEIDER, A. L. Coproduction of Public and Private Safety. The Western Political Quarterly. v. 40, n. 4, p. 611630, Dec. 1987.

; INGRAM, H. Policy design for democracy. Lawrence: University Press of Kansas, 1997.

SCHOMMER, P. C.; BUENO, R. U. H; KUNZLER, R. Coprodução de serviços públicos e gestão de resíduos sólidos: caminhos e obstáculos na experiência de um município catarinense. In: ENCONTRO DE ADMINISTRAÇÃO PÚBLICA E GOVERNANÇA -EnAPG, 4., 2010, Vitória. Anais... Vitória: ANPAD, 2010.

. et al. Coprodução e inovação social na esfera pública em debate no campo da gestão social. In: SCHOMMER, P. C.; BOULLOSA, R. F. (Org.). Gestão social como caminho para a redefinição da esfera pública. Florianópolis: Udesc, 2011, p. 31-70. (Coleção Enapegs, v. 5).

TENÓRIO, F. G. Gestão social: uma perspectiva conceitual. Rev. Adm. Pública, v. 32, n. 5, p. 7-23, Set./Out. 1998.

A modernidade e a pós-modernidade servidas em dois jantares. Cadernos EBAPE.BR, Rio de Janeiro, v. 7, n. 3, p. 473-491, Set. 2009. Disponível em: 〈http://www.scielo.br/pdf/cebape/v7n3/a06v7n3.pdf〉. Acesso em: 15 jun. 2014.

et al. Critérios para a avaliação de processos decisórios participativos deliberativos na implementação de políticas públicas. In: ENCONTRO DE ADMINISTRAÇÃO PÚBLICA E GOVERNANÇA - EnAPG, 3., 2008, Salvador. Anais... Salvador: ANPAD, 2008.

VERSCHUERE, B.; BRANDSEN, T.; PESTOFF, V. Co-production: the state of the art in research and the future agenda. International Journal of Voluntary and Nonprofit Organizations, v. 23, n. 4, p. 1083-1101, 2012.

VIZEU, F. Ação comunicativa e estudos organizacionais. Revista de Administração de Empresas, São Paulo, v. 45, n. 4, p. 10-21, Out./Dez. 2005.

Da racionalidade instrumental à racionalidade comunicativa: o caso de uma instituição psiquiátrica. Organizações \& Sociedade, Salvador, v. 13, n. 36, p. 163-184, Jan./Mar. 2006. Disponível em: <http://www2.revistaoes.ufba.br/viewarticle.php?id=255\&layout=abstract\&OJSSID=5260fdcd0e9fbde564884bdf1e9b7 584 >. Acesso em 11 jun. 2014.

Racionalidade administrativa e distorção comunicativa nas organizações contemporâneas. In: ENCONTRO DA ASSOCIAÇÃO NACIONAL DE PÓS-GRADUAÇÃO E PESQUISA EM ADMINISTRAÇÃO - ENANPAD, 33, 2009, São Paulo. Anais... São Paulo: ANPAD, 2009.

WHITAKeR, G. P. Coproduction: citizen participation in service delivery. Public Administration Review, v. 40, n. 3 , p. 240-246, Maio/Jun. 1980. 